\title{
Ammonium derivatives of chromenones and quinolinones as lead antimicrobial agents
}

\author{
SHILPI GUPTA ${ }^{\mathrm{a}}$, SEEMA SINGH ${ }^{\mathrm{b}, \mathrm{c}}$, ABHA KATHURIA ${ }^{\mathrm{a}}$, MANISH KUMAR $^{\mathrm{b}}$, \\ SWETA SHARMA $^{\mathrm{a}, \mathrm{d}}$, RAM KUMAR ${ }^{\mathrm{b}}$, VIRINDER S PARMAR ${ }^{\mathrm{a}}$, BHARAT SINGH $^{\mathrm{b}}$, \\ ANJALI GUPTA $^{\mathrm{a}}$, ERIK VAN DER EYCKEN ${ }^{\mathrm{d}}$, GAINDA L SHARMA ${ }^{\mathrm{b}, *}$ and \\ SUNIL K SHARMA ${ }^{\mathrm{a}, *}$ \\ aDepartment of Chemistry, University of Delhi, Delhi 110 007, India \\ ${ }^{b}$ Institute of Genomics and Integrative Biology, Delhi University Campus, Mall Road, Delhi 110 007, India \\ ${ }^{\mathrm{c}}$ Department of Biotechnology, Pune University, Pune 411 007, India \\ ${ }^{\mathrm{d}}$ Katholieke Universiteit Leuven (K.U.Leuven), Celestijnenlaan 200F, 3001, Leuven, Belgium \\ e-mail: sk.sharma90@gmail.com; drglsharma@ hotmail.com
}

MS received 15 March 2011; revised 14 June 2011; accepted 27 June 2011

\begin{abstract}
A series of novel ammonium derivatives were synthesized and examined for their antimicrobial efficacy. Comparison of antimicrobial spectrum revealed that compounds $\mathbf{9 , 1 1 , 1 6}$ and $\mathbf{2 3}$ had strong potential against pathogens in vitro. Cytotoxicity results showed compound $\mathbf{9}$ to be least toxic, it is non-toxic to A549 and U87 cells in MTT assay and exhibits marginal toxicity (15-20\%) to human erythrocytes at a concentration of $1000 \mu \mathrm{g} / \mathrm{ml}$ as compared to $100 \%$ lysis of cells by $31.25 \mu \mathrm{g} / \mathrm{ml}$ of the standard drug amphotericin B. This compound has MIC values in the range of $1.95-31.25 \mu \mathrm{g} /$ disc in DDA against different pathogens and may considered to be an important lead antimicrobial molecule for further exploration.
\end{abstract}

Keywords. Ammonium compounds; antimicrobial activity; chromenones; quinolinones.

\section{Introduction}

The occurrence of life-threatening infections caused by pathogenic microorganisms has been a cause of major concern globally, resulting in high mortality and morbidity. ${ }^{1}$ The search for compounds with antimicrobial activity has gained tremendous importance recently, due to the alarming increase in the number of infections caused by antibiotic-resistant microorganisms. ${ }^{2}$ Endemic and opportunistic fungal infections have become an important problem, along with the increasing number of patients undergoing immunosuppressive therapy. ${ }^{3-5}$ Although it was believed that virtually all bacterial infections could be treated with available antibacterial drugs, the drug resistance in bacteria is fast emerging and deaths following bacterial infections are on the rise even in patients infected with bacteria that are curable with currently available drugs. This is because the patients are at risk for infections caused by multidrug-resistant pathogens. ${ }^{6}$ Consequently, the

\footnotetext{
*For correspondence
}

identification of novel antibiotic classes with activity against resistant strains is critical to successful therapy of diseases caused by bacteria. ${ }^{7}$

Fungal infections including aspergillosis have emerged as threat to public health in recent years. Effective therapy of aspergillosis with currently available drugs is considered to be extremely difficult at late stages of infection and almost impossible when it becomes systemic. ${ }^{8}$ At present, amphotericin B and azoles remain the mainstay of systemic therapy ${ }^{9}$ despite their very severe side effects. Further, there are reports on the isolation of fungal pathogens that have been resistant to most antifungals. ${ }^{10-12}$ The success of the development of an ideal antifugal drug relies upon the identification of new molecules with broad spectrum of activity and novel targets having no counterpart in mammalian host. ${ }^{9,13}$ There have been studies exploring synthetic compounds and natural products as potential antifungal agents. Antimycotic activity of Datura metel has been demonstrated. ${ }^{14}$ Also in vitro, ${ }^{15}$ in vivo ${ }^{16}$ and post antifungal effect ${ }^{17}$ of 2-(3,4-dimethyl-2,5-dihydro- $1 H$-pyrrol-2-yl)-1methylethyl pentanoate) isolated from $D$. metel has been reported. Chhillar et al. screened a series of 
synthetic compounds and reported antimicrobial activity of dihydropyridines. ${ }^{18}$

Many natural and synthetic products consisting of chromenones and quinolinones have been shown to display diverse and interesting biological and pharmacological activities. Our group has been involved in the synthesis of various analogues of chromen2-ones, ${ }^{19,20}$ quinolin-2-ones ${ }^{21}$ and chromen-4-ones ${ }^{22}$ to study their pharmacological effects and antioxidant potential. ${ }^{19-22}$ Further, ammonium compounds are known for their antibacterial activity against both Gram-positive and Gram-negative bacteria, as well as against some pathogenic species of fungi and protozoa. ${ }^{23-28}$ The encouraging biological activity results of the two classes of heterocyclic compounds and based on the literature data on ammonium compounds, we envisioned that chromenones and quinolinones based ammonium compounds may possibly act as potent antimicrobial agents. In lieu of this, the present work was undertaken here; we synthesize a series of long chain ammonium derivatives of chromenones and quinolinones and screened them for antimicrobial activity.

\section{Experimental}

\subsection{General}

All the solvents were dried and distilled prior to their use. Reactions were monitored by precoated TLC plates (Merck silica gel $60 \mathrm{~F}_{254}$ ); the spots were visualized either by UV light, or by spraying with 5\% alcoholic $\mathrm{FeCl}_{3}$ solution. Silica gel (100-200 mesh) was used for column chromatography. Oxalyl chloride, 11bromo undecanoic acid, dihalo alkanes, and triethylamine were supplied by Spectrochem Pvt. Ltd., India. Potassium carbonate was fused in a muffle furnace at $400^{\circ} \mathrm{C}$ thrice prior to use. Melting points were recorded in capillaries in sulphuric acid bath and are uncorrected. Infrared spectra were recorded on PerkinElmer FT-IR model 9 spectrophotometer. The ${ }^{1} \mathrm{H}$ NMR and ${ }^{13} \mathrm{C}$ NMR spectra were recorded on Bruker AC$400(400 \mathrm{MHz}, 100.6 \mathrm{MHz}) \mathrm{NMR}$ spectrometer and Avance-300 (300 MHz, 75.5 MHz) NMR spectrometer using TMS as internal standard. The chemical shift values are on $\delta$ scale and the coupling constant values $(J)$ are in Hz. The HRMS spectra were recorded on Agilent-6210 ES-TOF, JEOL JMX-SX-102A and Waters LCT Micromass-KC455.

The chromenones and quinolin-2-ones were synthesized according to literature procedures..$^{20,21,29-31}$

\subsection{General procedure for the synthesis of} ammonium acyloxy derivatives of chromenones and quinolinones (9-16)

To an ice cold solution of 11-bromoundecanoic acid $(2.25 \mathrm{~g}, 8.48 \mathrm{mmol})$ in anhydrous $\operatorname{DCM}(25 \mathrm{~mL})$ was added oxalyl chloride ( $2.14 \mathrm{~g}, 16.96 \mathrm{mmol})$, the reaction mixture was stirred under nitrogen for $2 \mathrm{~h}$. The solvent was then removed in vacuo and the resulting yellow viscous oil was dissolved in THF $(20 \mathrm{~mL})$ and the solution was cooled to $5^{\circ} \mathrm{C}$. To this, a solution of one equivalent chromenones/quinolin-2-ones in THF was added followed by 1.0 equivalent of anhydrous triethyl amine. The reaction mixture was stirred at room temperature $\left(25^{\circ} \mathrm{C}\right)$ for about $6 \mathrm{~h}$, the solvent was then removed under reduced pressure and the resulting crude product was subjected to column chromatography to yield the corresponding bromo ester (1-8). To the solution of bromo ester $(\mathbf{1 - 8})$ in anhydrous acetonitrile $(20 \mathrm{~mL})$, was added triethylamine ( 5 equivalents) and the reaction mixture was stirred under nitrogen at $60^{\circ} \mathrm{C}$ for approximately $48 \mathrm{~h}$. The progress of reaction was monitored on TLC (methanol-chloroform (1:4)). On completion of the reaction, the solvent was evaporated under reduced pressure and the resultant product was then subjected to column chromatography to give the pure quaternary ammonium compound (9-16) in moderate to low yields (20-65\%) as off white or pale brown solid.

2.2a N,N,N-Triethyl-11-(4-methyl-2-oxo-2H-chromen7-yloxy)-11-oxoundecan-1-aminium bromide (9): The product was obtained through column chromatography using silica gel in methanol-chloroform (1:9) to give $9(32 \%)$ as a pale white solid. $\mathrm{mp}=72^{\circ} \mathrm{C}$; $\mathrm{R}_{f}=0.54$ (silica gel, methanol-chloroform (1:4)); UV (acetonitrile) $\lambda_{\max }: 270$ and $311 \mathrm{~nm}$; IR $(\mathrm{KBr})$ $v_{\max }: 3468.8,2977.9,2923.1,2851.6,1764.5,1724.9$, $1625.2,1613.9,1568.1,1504.0,1486.5,1466.5$, $1444.8,1412.9,1391.6,1368.5,1325.6,1262.6$, $1242.5,1219.1,1205.4,1188.0,1152.4,1131.0$, 1111.3, 1094.6, 1071.6, 1019.3, 998.1, 982.1, 918.5, 879.2, 854.8, 797.3, 579.2, 456.7, $434.3 \mathrm{~cm}^{-1}$; ${ }^{1} \mathrm{H}$ NMR $\left(400 \mathrm{MHz}, \mathrm{CDCl}_{3} ; \mathrm{Me}_{4} \mathrm{Si}\right): \delta$ 1.26-1.35 (m, $\left.21 \mathrm{H},-\mathrm{N}\left(\mathrm{CH}_{2} \mathrm{CH}_{3}\right)_{3}, \mathrm{H}-3^{\prime}-\mathrm{H}-8^{\prime}\right), 1.63-1.73(\mathrm{~m}, 4 \mathrm{H}$, $\mathrm{H}-2^{\prime}$ and $\left.\mathrm{H}_{-} 9^{\prime}\right), 2.39$ (s, 3H, C-4 $\left.\mathrm{CH}_{3}\right), 2.54(\mathrm{t}, 2 \mathrm{H}$, $\left.J=7.2 \mathrm{hz}, \mathrm{H}-10^{\prime}\right), 3.23\left(\mathrm{t}, 2 \mathrm{H}, J=7.1 \mathrm{hz}, \mathrm{H}-1^{\prime}\right)$, 3.44 (q, $\left.6 \mathrm{H}, J=6.9 \mathrm{hz},-\mathrm{N}\left(\mathrm{CH}_{2} \mathrm{CH}_{3}\right)_{3}\right), 6.20(\mathrm{~s}, 1 \mathrm{H}$, H-3), 7.01-7.03 (m, 2H, H-6 and H-8), $7.58(\mathrm{~d}, 1 \mathrm{H}, J=$ $9.2 \mathrm{hz}, \mathrm{H}-5) ;{ }^{13} \mathrm{C}$ NMR $\left(100.6 \mathrm{MHz}, \mathrm{CDCl}_{3} ; \mathrm{Me}_{4} \mathrm{Si}\right): \delta$ $7.95\left(-\mathrm{N}\left(\mathrm{CH}_{2} \mathrm{CH}_{3}\right)_{3}\right), 18.66\left(\mathrm{C}-4 \mathrm{CH}_{3}\right), 21.95,24.56$, 26.33, 28.74, 28.97, 29.11, 29.44, 29.57, 34.14 (C-2' - 
C-10'), $53.38\left(-\mathrm{N}\left(\mathrm{CH}_{2} \mathrm{CH}_{3}\right)_{3}\right), 57.39\left(\mathrm{C}-1^{\prime}\right), 110.19$ (C-8), 114.17 (C-3), 117.60 and 118.08 (C-6 and C-10), 125.41 (C-5), 152.10, 153.04 and 153.92 (C-4, C-7 and C-9), 160.41 (C-2) and 171.53 (C-11'); HRMS, $m / z: \mathrm{M}^{+}$calculated for $\mathrm{C}_{27} \mathrm{H}_{42} \mathrm{NO}_{4}^{+}$: 444.3114, found 444.3115 .

2.2b N,N,N-Triethyl-11-(3-ethyl-4-methyl-2-oxo-2Hchromen-7-yloxy)-11-oxoundecan-1-aminium bromide (10): The product was obtained through column chromatography using silica gel in methanol-chloroform (1:9) to give $\mathbf{1 0}(22 \%)$ as a pale white solid. $\mathrm{mp}=$ $68-70^{\circ} \mathrm{C} ; \mathrm{R}_{f}=0.45$ (silica gel, methanol-chloroform (1:4)); UV (acetonitrile) $\lambda_{\max }: 270$ and $315 \mathrm{~nm}$; IR (KBr) $v_{\max }: 3419.7,3054.2$, 2926.6, 2855.2, 1756.1, $1717.3,1645.3,1568.1,1509.5,1456.2,1394.1$, 1299.2, 1248.9, 1184.5, 1141.3, 1055.2, 1007.9, 937.9, 913.5, 798.3, 725.2, 688.1 $\mathrm{cm}^{-1} ;{ }^{1} \mathrm{H}$ NMR $(300 \mathrm{MHz}$, $\left.\mathrm{CDCl}_{3} ; \mathrm{Me}_{4} \mathrm{Si}\right): \delta 1.10\left(\mathrm{t}, 3 \mathrm{H}, J=7.5 \mathrm{hz}, \mathrm{H}-2^{\prime \prime}\right)$, 1.19-1.50 (m, 21H, $-\mathrm{N}\left(\mathrm{CH}_{2} \mathrm{CH}_{3}\right)_{3}$ and $\left.\mathrm{H}-3^{\prime}-\mathrm{H}-8^{\prime}\right)$, $1.69-1.72\left(\mathrm{~m}, 4 \mathrm{H}, \mathrm{H}-2^{\prime}\right.$ and $\left.\mathrm{H}-9^{\prime}\right), 2.46$ (s, 3H, C-4 $\left.\mathrm{CH}_{3}\right), 2.58\left(\mathrm{t}, 2 \mathrm{H}, J=7.1 \mathrm{hz}, \mathrm{H}-10^{\prime}\right), 2.77(\mathrm{q}, 2 \mathrm{H}$, $\left.J=6.9 \mathrm{hz}, \mathrm{H}-1^{\prime \prime}\right), 3.22$ (t, $\left.2 \mathrm{H}, J=6.6 \mathrm{hz}, \mathrm{H}-1^{\prime}\right), 3.45-$ $3.58\left(\mathrm{~m}, 6 \mathrm{H},-\mathrm{N}\left(\mathrm{CH}_{2} \mathrm{CH}_{3}\right)_{3}\right), 6.93(\mathrm{dd}, 1 \mathrm{H}, J=2.1$ and $8.7 \mathrm{hz}, \mathrm{H}-6), 7.26$ (d, $1 \mathrm{H}, J=2.1 \mathrm{hz}, \mathrm{H}-8), 7.68$ $(\mathrm{d}, 1 \mathrm{H}, J=9.0 \mathrm{hz}, \mathrm{H}-5) ;{ }^{13} \mathrm{C} \mathrm{NMR}\left(75.5 \mathrm{MHz}, \mathrm{CDCl}_{3}\right.$; $\left.\mathrm{Me}_{4} \mathrm{Si}\right): \delta 8.07\left(-\mathrm{N}\left(\mathrm{CH}_{2} \mathrm{CH}_{3}\right)_{3}\right), 13.41\left(\mathrm{C}-2^{\prime \prime}\right), 15.00$ $\left(\mathrm{C}-4 \mathrm{CH}_{3}\right), 20.21\left(\mathrm{C}-1^{\prime \prime}\right), 21.98,22.65,24.71,25.28$, 26.37, 26.91, 28.97, 31.59, $34.29\left(\mathrm{C}-2^{\prime}-\mathrm{C}-10^{\prime}\right), 53.50$ $\left(-\mathrm{N}\left(\mathrm{CH}_{2} \mathrm{CH}_{3}\right)_{3}\right), 57.54\left(\mathrm{C}-1^{\prime}\right), 108.52(\mathrm{C}-8), 116.37$ and 118.93 (C-6 and C-10), 125.51 (C-3), 132.46 (C-5), 142.51 (C-4), 151.28 and 152.22 (C-7 and C-9), $163.31(\mathrm{C}-2)$ and $172.17\left(\mathrm{C}-11^{\prime}\right)$; HRMS, $m / z: \mathrm{M}^{+}$. and $[\mathrm{M}-\mathrm{H}]^{+}$calculated for $\mathrm{C}_{29} \mathrm{H}_{46} \mathrm{NO}_{4}^{+}: 472.3421$ and 471.3460, found 472.4185 and 471.4941 respectively.

2.2c N,N,N-Triethyl-11-(3-hexyl-4-methyl-2-oxo-2Hchromen-7-yloxy)-11-oxoundecan-1-aminium bromide (11): The product was obtained through column chromatography using silica gel in methanol-chloroform (1:9) to give $\mathbf{1 1}(24 \%)$ as a pale white solid. $\mathrm{mp}=$ $51-52^{\circ} \mathrm{C} ; \mathrm{R}_{f}=0.54$ (silica gel, methanol-chloroform (1:4)); UV (acetonitrile) $\lambda_{\max }: 274$ and $313 \mathrm{~nm}$; IR (KBr) $v_{\max }: 3432.1,3080.2,2926.6,2854.0,2739.1$, $2677.9,2491.8,1759.6,1717.3,1617.4,1466.6$, $1383.5,1270.2,1250.3,1156.3,1034.9,928.1,883.8$, 827.4, 778.1, 736.0, $462.0 \mathrm{~cm}^{-1}$; ${ }^{1} \mathrm{H}$ NMR $(300 \mathrm{MHz}$, $\mathrm{CDCl}_{3} ; \mathrm{Me}_{4} \mathrm{Si}$ ): $\delta 0.89$ (t, $\left.3 \mathrm{H}, J=7.2 \mathrm{hz}, \mathrm{H}-6^{\prime \prime}\right), 1.32-$ $1.51\left(\mathrm{~m}, 29 \mathrm{H},-\mathrm{N}\left(\mathrm{CH}_{2} \mathrm{CH}_{3}\right)_{3}, \mathrm{H}-3^{\prime}-\mathrm{H}-8^{\prime}\right.$ and $\mathrm{H}-2^{\prime \prime}-$ $\mathrm{H}-5^{\prime \prime}$ ), 1.71-1.73 (m, 4H, H-2' and H-9'), 2.41 (s, 3H, C-4 $\mathrm{CH}_{3}$ ), 2.62-2.66 (m, 4H, H-1" and $\left.\mathrm{H}-10^{\prime}\right), 3.27$ $\left(\mathrm{t}, 2 \mathrm{H}, J=6.6 \mathrm{hz}, \mathrm{H}-1^{\prime}\right), 3.50(\mathrm{q}, 6 \mathrm{H}, J=6.9 \mathrm{hz}$, $\left.-\mathrm{N}\left(\mathrm{CH}_{2} \mathrm{CH}_{3}\right)_{3}\right), 6.92-7.05$ (m, 2H, H-6 and H-8), 7.61 $(\mathrm{d}, 1 \mathrm{H}, J=9.3 \mathrm{hz}, \mathrm{H}-5) ;{ }^{13} \mathrm{C} \mathrm{NMR}\left(75.5 \mathrm{MHz}, \mathrm{CDCl}_{3}\right.$; $\left.\mathrm{Me}_{4} \mathrm{Si}\right): \delta 8.07\left(-\mathrm{N}\left(\mathrm{CH}_{2} \mathrm{CH}_{3}\right)_{3}\right), 14.02\left(\mathrm{C}-6^{\prime \prime}\right), 14.92$ $\left(\mathrm{C}-4 \mathrm{CH}_{3}\right), 22.05,22.54,24.65,26.43,27.62,28.63$, 28.82, 28.97, 29.06, 29.18, 29.28, 29.61, 31.61, 34.22 $\left(\mathrm{C}-2^{\prime}-\mathrm{C}-10^{\prime}\right.$ and C-1" $\left.-\mathrm{C}-5^{\prime \prime}\right), 53.50\left(-\mathrm{N}\left(\mathrm{CH}_{2} \mathrm{CH}_{3}\right)_{3}\right)$, $57.54\left(\mathrm{C}-1^{\prime}\right), 109.85(\mathrm{C}-8), 117.87$ and 118.47 (C-6 and C-10), 125.25 (C-3), 126.33 (C-5), 145.39 (C-4), 151.98 and 152.48 (C-7 and C-9), 161.41 (C-2) and $171.74\left(\mathrm{C}-11^{\prime}\right)$; HRMS, $m / z: \mathrm{M}^{+\cdot}$ and $[\mathrm{M}+1]^{+}$calculated for $\mathrm{C}_{33} \mathrm{H}_{54} \mathrm{NO}_{4}^{+}: 528.4053$ and 529.4086 , found 528.1099 and 529.1401, respectively.

2.2d N,N,N-Triethyl-11-(3-decyl-4-methyl-2-oxo-2Hchromen-7-yloxy)-11-oxoundecan-1-aminium bromide (12): The product was obtained through column chromatography using silica gel in methanol-chloroform (1:9) to give $\mathbf{1 2}(30 \%)$ as a brown solid. $\mathrm{mp}=64-65^{\circ} \mathrm{C}$; $\mathrm{R}_{f}=0.6$ (silica gel, methanol-chloroform (1:4)); UV (acetonitrile) $\lambda_{\max }: 275$ and $310 \mathrm{~nm}$; IR $(\mathrm{KBr})$ $v_{\max }: 3429.1,3075.6,2927.1,2854.9,2745.1,2678.2$, $2487.4,1758.8,1717.9,1617.4,1464.8,1383.2$, 1270.1, 1155.6, 1032.9, 927.7, 797.1, $463.4 \mathrm{~cm}^{-1}$; ${ }^{1} \mathrm{H}$ NMR $\left(300 \mathrm{MHz}, \mathrm{CDCl}_{3} ; \mathrm{Me}_{4} \mathrm{Si}\right): \delta 0.88(\mathrm{t}, 3 \mathrm{H}$, $\left.J=7.1 \mathrm{hz}, \mathrm{H}-10^{\prime \prime}\right), 1.28-1.61\left(\mathrm{~m}, 37 \mathrm{H},-\mathrm{N}\left(\mathrm{CH}_{2} \mathrm{CH}_{3}\right)_{3}\right.$, $\mathrm{H}-3^{\prime}-\mathrm{H}-8^{\prime}$ and $\left.\mathrm{H}-2^{\prime \prime}-\mathrm{H}-9^{\prime \prime}\right), 2.30-2.34\left(\mathrm{~m}, 4 \mathrm{H}, \mathrm{H}-2^{\prime}\right.$ and $\left.\mathrm{H}-9^{\prime}\right), 2.41$ (s, 3H, C-4 $\mathrm{CH}_{3}$ ), $2.59-2.64$ (m, 4H, $\mathrm{H}-1^{\prime \prime}$ and $\left.\mathrm{H}-10^{\prime}\right), 3.27\left(\mathrm{t}, 2 \mathrm{H}, J=6.9 \mathrm{hz}, \mathrm{H}-1^{\prime}\right), 3.50$ $\left(\mathrm{q}, 6 \mathrm{H}, J=6.6 \mathrm{hz},-\mathrm{N}\left(\mathrm{CH}_{2} \mathrm{CH}_{3}\right)_{3}\right), 7.05-7.08(\mathrm{~m}$, 1H, H-6), 7.29 (s, 1H, H-8), 7.63 (d, 1H, $J=8.5 \mathrm{hz}$, $\mathrm{H}-5) ;{ }^{13} \mathrm{C}$ NMR $\left(75.5 \mathrm{MHz}, \mathrm{CDCl}_{3} ; \mathrm{Me}_{4} \mathrm{Si}\right): \delta 8.06$ $\left(-\mathrm{N}\left(\mathrm{CH}_{2} \mathrm{CH}_{3}\right)_{3}\right), 14.10\left(\mathrm{C}-10^{\prime \prime}\right), 14.97 \quad\left(\mathrm{C}-4 \mathrm{CH}_{3}\right)$, 22.05, 22.65, 24.71, 26.92, 25.89, 26.45, 27.69, 28.61, $28.73,29.11,29.20,29.34,29.28,29.42,29.58,31.86$, 34.06, 34.37 (C-2' - C-10' and C-1" - C-9"), 53.52 $\left(-\mathrm{N}\left(\mathrm{CH}_{2} \mathrm{CH}_{3}\right)_{3}\right), 57.52\left(\mathrm{C}-1^{\prime}\right), 109.91$ (C-8), 117.91 and 118.53 (C-6 and C-10), 125.30 (C-3), 126.40 (C-5), 145.44 (C-4), 152.05 and 152.54 (C-7 and C-9), $161.49(\mathrm{C}-2)$ and $171.80\left(\mathrm{C}-11^{\prime}\right)$; HRMS, $m / z: \mathrm{M}^{+}$ calculated for $\mathrm{C}_{37} \mathrm{H}_{62} \mathrm{NO}_{4}^{+}$: 584.4700 , found 584.4585 .

2.2e N,N,N-Triethyl-11-(4-methyl-2-oxo-1,2-dihydroquinolin-7-yloxy)-11-oxoundecan-1-aminium bromide (13): The product was obtained through column chromatography using silica gel in methanol-chloroform (1:9) to give $\mathbf{1 3}(30 \%)$ as a pale white solid. $\mathrm{mp}=$ $156^{\circ} \mathrm{C} ; \mathrm{R}_{f}=0.6$ (silica gel, methanol-chloroform (1:4)); UV (acetonitrile) $\lambda_{\max }: 275$ and $326 \mathrm{~nm}$; IR (KBr) $v_{\max }: 3422.2,2980.4,2923.9,2849.0,1768.5$, $1655.1,1602.8,1560.3,1458.6,1395.6,1253.1$, 
1166.3, 1141.7, 1128.2, 1021.3, 888.5, 813.7, 724.5 and $567.8 \mathrm{~cm}^{-1}$; ${ }^{1} \mathrm{H}$ NMR (DMSO- $d_{6}, 300 \mathrm{MHz}$; $\mathrm{Me}_{4} \mathrm{Si}$ ): $\delta 1.14$ (brs, 9H, $\left.-\mathrm{N}\left(\mathrm{CH}_{2} \mathrm{CH}_{3}\right)_{3}\right), 1.29$ (brs, $\left.12 \mathrm{H}, \mathrm{H}-3^{\prime}-\mathrm{H}-8^{\prime}\right), 1.55-1.63\left(\mathrm{~m}, 4 \mathrm{H}, \mathrm{H}-2^{\prime}\right.$ and $\mathrm{H}-$ $\left.9^{\prime}\right), 2.40\left(\mathrm{~s}, 3 \mathrm{H}, \mathrm{C}-4 \mathrm{CH}_{3}\right), 2.60(\mathrm{t}, 2 \mathrm{H}, J=6.6 \mathrm{hz}$, $\left.\mathrm{H}-10^{\prime}\right), 3.08$ (t, 2H, $\left.J=6.9 \mathrm{hz}, \mathrm{H}-1^{\prime}\right), 3.20$ (q, 6H, $\left.J=6.6 \mathrm{hz},-\mathrm{N}\left(\mathrm{CH}_{2} \mathrm{CH}_{3}\right)_{3}\right), 6.37$ (s, 1H, H-3), 6.95 (d, $1 \mathrm{H}, J=8.7 \mathrm{hz}, \mathrm{H}-6), 7.03$ (s, 1H, H-8), 7.73 (d, 1H, $J=8.1 \mathrm{hz}, \mathrm{H}-5)$ and 11.66 (brs, $1 \mathrm{H}, \mathrm{NH}) ;{ }^{13} \mathrm{C} \mathrm{NMR}$ (DMSO- $\left.d_{6}, 75.5 \mathrm{MHz} ; \mathrm{Me}_{4} \mathrm{Si}\right): \delta 7.14\left(-\mathrm{N}\left(\mathrm{CH}_{2} \mathrm{CH}_{3}\right)_{3}\right)$, $18.52\left(\mathrm{C}-4 \mathrm{CH}_{3}\right), 20.90,24.21,25.76,28.31,28.46$, $28.60,28.69,28.72,33.40\left(\mathrm{C}-2^{\prime}-\mathrm{C}-10^{\prime}\right), 51.90$ ($\left.\mathrm{N}\left(\mathrm{CH}_{2} \mathrm{CH}_{3}\right)_{3}\right), 55.94\left(\mathrm{C}-1^{\prime}\right), 107.87(\mathrm{C}-6), 115.83$ and 117.46 (C-8 and C-10), 120.31 (C-3), 126.15 (C-5), 139.52 (C-9), 147.69 (C-4), 151.66 (C-7), 161.73 (C-2) and $171.60\left(\mathrm{C}-11^{\prime}\right)$; HRMS, $m / z: \mathrm{M}^{+}$. calculated for $\mathrm{C}_{27} \mathrm{H}_{43} \mathrm{O}_{3} \mathrm{~N}_{2}$ : 443.3268, found 443.3315 .

2.2f N,N,N-Triethyl-11-(3-ethyl-4-methyl-2-oxo-1,2dihydroquinolin-7-yloxy)-11-oxoundecan-1-aminium bromide (14): The product was obtained through column chromatography using silica gel in methanolchloroform (1:9) to give $\mathbf{1 4}(33 \%)$ as a pale white solid. $\mathrm{mp}=80^{\circ} \mathrm{C} ; \mathrm{R}_{f}=0.6$ (silica gel, methanol-chloroform (1:4)); UV (acetonitrile) $\lambda_{\max }: 270$ and $328 \mathrm{~nm}$; IR (KBr) $v_{\max }: 3379.8,2929.3,2855.6,1757.9,1642.2$, $1509.3,1459.9, \quad 1393.8,1301.1,1248.9,1186.1$, 1156.7, 1141.8, 1110.7, 1055.5, 1008.3, 974.8, 911.7, 793.2, 757.3 and $687.7 \mathrm{~cm}^{-1} ;{ }^{1} \mathrm{H}$ NMR (DMSO- $d_{6}$, $300 \mathrm{MHz} ; \mathrm{Me}_{4} \mathrm{Si}$ ): $\delta 0.99$ (t, $3 \mathrm{H}, J=7.5 \mathrm{hz}, \mathrm{H}-2^{\prime \prime}$ ), 1.06 (brs, 9H, - $\left.\mathrm{N}\left(\mathrm{CH}_{2} \mathrm{CH}_{3}\right)_{3}\right), 1.13$ (brs, $12 \mathrm{H}, \mathrm{H}-3^{\prime}-$ $\left.\mathrm{H}-8^{\prime}\right), 1.54-1.62$ (m, 4H, H-2' and $\left.\mathrm{H}^{\prime} 9^{\prime}\right), 2.34$ (s, 3H, C-4 $\left.\mathrm{CH}_{3}\right), 2.58-2.62\left(\mathrm{~m}, 4 \mathrm{H}, \mathrm{H}-1^{\prime \prime}\right.$ and $\left.\mathrm{H}-10^{\prime}\right), 3.07$ $\left(\mathrm{t}, 2 \mathrm{H}, J=7.8 \mathrm{hz}, \mathrm{H}-1^{\prime}\right), 3.19(\mathrm{q}, 6 \mathrm{H}, J=6.6 \mathrm{hz}$, $\left.-\mathrm{N}\left(\mathrm{CH}_{2} \mathrm{CH}_{3}\right)_{3}\right), 6.91(\mathrm{~d}, 1 \mathrm{H}, J=2.1$ and $8.7 \mathrm{hz}, \mathrm{H}-6)$, $6.99(\mathrm{~s}, 1 \mathrm{H}, \mathrm{H}-8), 7.75(\mathrm{~d}, 1 \mathrm{H}, J=8.7 \mathrm{hz}, \mathrm{H}-5)$ and 11.67 (brs, $1 \mathrm{H}, \mathrm{NH}) ;{ }^{13} \mathrm{C}$ NMR (DMSO- $d_{6}, 75.5 \mathrm{MHz}$; $\left.\mathrm{Me}_{4} \mathrm{Si}\right): \delta 7.17\left(-\mathrm{N}\left(\mathrm{CH}_{2} \mathrm{CH}_{3}\right)_{3}\right), 13.17\left(\mathrm{C}-2^{\prime \prime}\right), 14.53$ $\left(\mathrm{C}-4 \mathrm{CH}_{3}\right), 19.51\left(\mathrm{C}-1^{\prime \prime}\right), 20.92,24.30,25.78,26.30$, 28.32, 28.45, 28.59, 28.72, $33.42\left(\mathrm{C}-2^{\prime}-\mathrm{C}-10^{\prime}\right), 51.95$ $\left(-\mathrm{N}\left(\mathrm{CH}_{2} \mathrm{CH}_{3}\right)_{3}\right), 56.00\left(\mathrm{C}-1^{\prime}\right), 107.44(\mathrm{C}-6), 115.62$ and 117.90 (C-8 and C-10), 125.91 (C-3), 132.06 (C5), 137.84 (C-9), 141.26 (C-4), 150.75 (C-7), 161.45 (C-2) and $171.60\left(\mathrm{C}-11^{\prime}\right)$; HRMS, $m / z: \mathrm{M}^{+}$. calculated for $\mathrm{C}_{29} \mathrm{H}_{47} \mathrm{O}_{3} \mathrm{~N}_{2}$ : 471.3581, found 471.3471.

2.2g N,N,N-Triethyl-11-(4-oxo-4H-1-benzopyran-7yloxy)-11-oxoundecan-1-aminium bromide (15): The product was obtained through column chromatogra- phy using silica gel in methanol-chloroform (1:9) to give $15(65 \%)$ as a white crystalline solid. $\mathrm{mp}=$ $81-82^{\circ} \mathrm{C} ; \mathbf{R}_{f}=0.4$ (silica gel, methanol-chloroform (1:4)); UV (acetonitrile) $\lambda_{\max }: 292$ and $301 \mathrm{~nm}$; IR (KBr) $v_{\max }: 2924.3,2854.7,1762.0,1638.5,1437.1$, 1396.1, 1254.4, 1140.2, 1004.0, 832.3 $\mathrm{cm}^{-1} ;{ }^{1} \mathrm{H}$ NMR $\left(300 \mathrm{MHz}, \mathrm{CDCl}_{3} ; \mathrm{Me}_{4} \mathrm{Si}\right): \delta 1.28-1.39(\mathrm{~m}, 21 \mathrm{H}$, $-\mathrm{N}\left(\mathrm{CH}_{2} \mathrm{CH}_{3}\right)_{3}$ and $\left.\mathrm{H}-3^{\prime}-\mathrm{H}-8^{\prime}\right), 1.60-1.78(\mathrm{~m}, 4 \mathrm{H}$, $\mathrm{H}-2^{\prime}$ and $\left.\mathrm{H}-9^{\prime}\right), 2.61$ (t, $\left.2 \mathrm{H}, J=7.3 \mathrm{hz}, \mathrm{H}-10^{\prime}\right), 3.28$ $\left(\mathrm{t}, 2 \mathrm{H}, J=7.2 \mathrm{hz}, \mathrm{H}-1^{\prime}\right), 3.50(\mathrm{q}, 6 \mathrm{H}, J=6.8 \mathrm{hz}$, $\left.-\mathrm{N}\left(\mathrm{CH}_{2} \mathrm{CH}_{3}\right)_{3}\right), 6.33(\mathrm{~d}, 1 \mathrm{H}, J=6.0 \mathrm{hz}, \mathrm{H}-3), 7.15$ $(\mathrm{d}, 1 \mathrm{H}, J=8.7 \mathrm{hz}, \mathrm{H}-6), 7.31(\mathrm{~s}, 1 \mathrm{H}, \mathrm{H}-8), 7.88$ $(\mathrm{d}, 1 \mathrm{H}, J=6.0 \mathrm{hz}, \mathrm{H}-2), 8.20(\mathrm{~d}, 1 \mathrm{H}, J=8.7 \mathrm{hz}$, $\mathrm{H}-5) ;{ }^{13} \mathrm{C}$ NMR $\left(75.5 \mathrm{MHz}, \mathrm{CDCl}_{3} ; \mathrm{Me}_{4} \mathrm{Si}\right): \delta 7.96$ $\left(-\mathrm{N}\left(\mathrm{CH}_{2} \mathrm{CH}_{3}\right)_{3}\right), 21.95,24.54,24.73,26.31,28.79$, $28.97,29.15,33.91,34.16\left(\mathrm{C}-2^{\prime}-\mathrm{C}-10^{\prime}\right), 53.35$ $\left(-\mathrm{N}\left(\mathrm{CH}_{2} \mathrm{CH}_{3}\right)_{3}\right), 57.35\left(\mathrm{C}-1^{\prime}\right), 111.03(\mathrm{C}-8), 112.93$ (C-3), 119.50 (C-6), 122.41 and 126.97 (C-5 and C-10), 152.11 (C-2), 154.30 and 156.89 (C-7 and C-9), $171.37\left(\mathrm{C}-11^{\prime}\right)$ and 176.77 (C-4); HRMS, $m / z$ : $[\mathrm{M}+\mathrm{H}]^{+}$calculated for $\mathrm{C}_{26} \mathrm{H}_{40} \mathrm{NO}_{4}^{+}$: 431.2991, found 431.4231 .

2.2h N,N,N-triethyl-11-(3-hexyl-4-oxo-4H-chromen7-yloxy)-11-oxoundecan-1-aminium bromide (16): The product was obtained through column chromatography using silica gel in methanol-chloroform (1:9) to give $16(27 \%)$ as a orange solid. $\mathrm{mp}=64-65^{\circ} \mathrm{C}$; $\mathrm{R}_{f}=0.52$ (silica gel, methanol-chloroform (1:4)); UV (acetonitrile) $\lambda_{\max }: 278$ and $305 \mathrm{~nm}$; IR $(\mathrm{KBr})$ $v_{\max }: 3425.1,2926.4,2855.1,1763.1,1646.5,1616.9$, 1440.7, 1396.1, 1228.2, 1167.9, 1112.5, 793.2, $\mathrm{cm}^{-1}$; ${ }^{1} \mathrm{H}$ NMR $\left(300 \mathrm{MHz}, \mathrm{CDCl}_{3} ; \mathrm{Me}_{4} \mathrm{Si}\right): \delta 0.87(\mathrm{t}, 3 \mathrm{H}$, $\left.J=7.5 \mathrm{hz}, \mathrm{H}-6^{\prime \prime}\right), 1.17-1.46$ (m, 29H, $-\mathrm{N}\left(\mathrm{CH}_{2} \mathrm{CH}_{3}\right)_{3}$, H-3' $-\mathrm{H}-8^{\prime}$ and H-2" - H-5"), 1.55-1.62 (m, 2H, H-9'), $1.72-1.80\left(\mathrm{~m}, 2 \mathrm{H}, \mathrm{H}-2^{\prime}\right), 2.44(\mathrm{t}, 2 \mathrm{H}, J=7.0 \mathrm{hz}$, $\left.\mathrm{H}-10^{\prime}\right), 2.60$ (t, 2H, $\left.J=7.2 \mathrm{hz}, \mathrm{H}-1^{\prime \prime}\right), 3.26(\mathrm{t}, 2 \mathrm{H}, J=$ $\left.7.2 \mathrm{hz}, \mathrm{H}-1^{\prime}\right), 3.49$ (q, 6H, $\left.J=6.0 \mathrm{hz},-\mathrm{N}\left(\mathrm{CH}_{2} \mathrm{CH}_{3}\right)_{3}\right)$, $7.11(\mathrm{dd}, 1 \mathrm{H}, J=2.1$ and $8.7 \mathrm{hz}, \mathrm{H}-6), 7.22(\mathrm{~d}, 1 \mathrm{H}$, $J=2.1 \mathrm{hz}, \mathrm{H}-8), 7.75$ (s, 1H, H-2), 8.22 (d, 1H, $J=$ $8.7 \mathrm{hz}, \mathrm{H}-5) ;{ }^{13} \mathrm{C}$ NMR $\left(75.5 \mathrm{MHz}, \mathrm{CDCl}_{3} ; \mathrm{Me}_{4} \mathrm{Si}\right)$ : $\delta 8.11\left(-\mathrm{N}\left(\mathrm{CH}_{2} \mathrm{CH}_{3}\right)_{3}\right), 14.06\left(\mathrm{C}-6^{\prime \prime}\right), 22.09,22.56$, 24.68, 26.91, 25.70, 26.43, 28.43, 28.92, 29.08, 29.15, 29.26, 29.65, 31.59, 34.30 (C-2' - C-10' and C-1" $\left.\mathrm{C}-5^{\prime \prime}\right), 53.54\left(-\mathrm{N}\left(\mathrm{CH}_{2} \mathrm{CH}_{3}\right)_{3}\right), 57.54\left(\mathrm{C}-1^{\prime}\right), 110.84$ (C-8), 119.14 and 121.59 (C-6 and C-10), 124.90 (C-3), 127.17 (C-5), 152.11 (C-2), 154.30 and 156.89 (C-7 and $\mathrm{C}-9), 171.52\left(\mathrm{C}-11^{\prime}\right)$ and $177.16(\mathrm{C}-4)$; HRMS, $m / z: \mathrm{M}^{+}$and $[\mathrm{M}+1]^{+}$calculated for $\mathrm{C}_{32} \mathrm{H}_{52} \mathrm{NO}_{4}^{+}$: 514.7590, found 514.8330 . 
2.3 General procedure for the synthesis of ammonium alkoxy derivative of chromen-2-one (20-23)

To a flask containing 7-hydroxy-4-methyl coumarin $(1.0 \mathrm{~g}, \quad 5.68 \mathrm{mmol})$, in acetone $(25 \mathrm{~mL})$ and 2.0 equivalent of fused potassium carbonate was added 1.2 equivalent of 1-bromo-3-chloropropane/1, 6dibromohexane/1,10-dibromodecane, the reaction mixture was refluxed for $24 \mathrm{~h}$. The mixture was then filtered through celite and the solvent was evaporated in vacuo. The solid residue so obtained was purified by column chromatography to give corresponding halo alkoxy derivatives of chromen-2-one (17-19) as white crystalline solid. A mixture of $\mathbf{1 7}^{32}$ $(1.0 \mathrm{~g}, 3.96 \mathrm{mmol}) / \mathbf{1 8} \mathbf{8}^{33}(1.0 \mathrm{~g}, 2.95 \mathrm{mmol}) / \mathbf{1 9}(1.0 \mathrm{~g}$, $2.53 \mathrm{mmol})$, toluene $(8 \mathrm{~mL})$, acetone $(4 \mathrm{~mL})$, and $\mathrm{DMF}$ $(0.5 \mathrm{~mL})$ was heated at $50^{\circ} \mathrm{C}$. Then trialkyl amine $\left(\mathrm{NEt}_{3} / \mathrm{NBu}_{3}\right)$ (2 equivalent) was added to the mixture in $1 \mathrm{~h}$. The mixture was refluxed for a period of $48 \mathrm{~h}$, the solvent was evaporated under reduced pressure and the crude product was purified by flash column chromatography to give $\mathbf{2 0}(400 \mathrm{mg}, 32 \%)$ or $\mathbf{2 1}(725 \mathrm{mg}$, $68 \%)$ or $\mathbf{2 2}(860 \mathrm{mg}, 66 \%)$ or $\mathbf{2 3}(686 \mathrm{mg}, 65 \%)$.

2.3a N,N,N-Triethyl-3-(4-methyl-2-oxo-2H-chromen7-yloxy)propan-1-aminium chloride (20): The product was obtained through column chromatography using silica gel in methanol-chloroform (1:9) to give $20(32 \%)$ as a light green colour solid. $\mathrm{mp}=221-$ $223^{\circ} \mathrm{C} ; \mathrm{R}_{f}=0.27$ (silica gel, methanol-chloroform (1:4)); UV (acetonitrile) $\lambda_{\max }: 316 \mathrm{~nm}$; IR (KBr) $v_{\max }: 3447.9,3022.8,3003.7,2979.4,2943.2,2878.5$, $1710.9,1625.1,1556.7,1494.3,1470.9,1438.9$, $1427.6, \quad 1393.6, \quad 1382.9, \quad 1373.2, \quad 1326.2,1297.1$, $1197.5,1154.1,1076.5,1008.1,991.1,890.9,857.3$, $798.5,750.3,711.9, \quad 575.7,544.2,452.2 \mathrm{~cm}^{-1} ;{ }^{1} \mathrm{H}$ NMR (400 MHz, DMSO- $\left.d_{6} ; \mathrm{Me}_{4} \mathrm{Si}\right): \delta 1.20(\mathrm{t}, 9 \mathrm{H}$, $\left.J=7.0 \mathrm{hz},-\mathrm{N}\left(\mathrm{CH}_{2} \mathrm{CH}_{3}\right)_{3}\right), 2.08-2.15\left(\mathrm{~m}, 2 \mathrm{H}, \mathrm{H}-2^{\prime}\right)$, $2.40\left(\mathrm{~s}, 3 \mathrm{H}, \mathrm{C}-4 \mathrm{CH}_{3}\right), 3.29-3.31\left(\mathrm{~m}, 8 \mathrm{H}, \mathrm{N}\left(\mathrm{CH}_{2} \mathrm{CH}_{3}\right)_{3}\right.$ and $\left.H-1^{\prime}\right), 4.19\left(\mathrm{t}, 2 \mathrm{H}, J=6.6 \mathrm{hz}, \mathrm{H}-3^{\prime}\right), 6.23$ $(\mathrm{s}, 1 \mathrm{H}, \mathrm{H}-3), 6.97(\mathrm{dd}, 1 \mathrm{H}, J=2.4$ and $8.8 \mathrm{hz}$, $\mathrm{H}-6), 7.00(\mathrm{~d}, 1 \mathrm{H}, J=2.4 \mathrm{hz}, \mathrm{H}-8), 7.71(\mathrm{~d}, 1 \mathrm{H}$, $J=8.8 \mathrm{hz}, \mathrm{H}-5) ;{ }^{13} \mathrm{C}$ NMR $\left(100.6 \mathrm{MHz}, \mathrm{DMSO}-d_{6}\right.$; $\left.\mathrm{Me}_{4} \mathrm{Si}\right): \delta 7.08\left(-\mathrm{N}\left(\mathrm{CH}_{2} \mathrm{CH}_{3}\right)_{3}\right), 18.07\left(\mathrm{C}-4 \mathrm{CH}_{3}\right)$, $21.14\left(\mathrm{C}-2^{\prime}\right), 52.00\left(-\mathrm{N}\left(\mathrm{CH}_{2} \mathrm{CH}_{3}\right)_{3}\right), 53.06\left(\mathrm{C}-1^{\prime}\right)$, $65.13\left(\mathrm{C}-3^{\prime}\right), 101.21(\mathrm{C}-8), 111.24,112.36$ and 113.30 (C-3, C-6 and C-10), 126.50 (C-5), 153.34 and 154.60 (C-4 and C-9), 160.01 (C-7), 161.05 (C-2); HRMS, $m / z: \mathrm{M}^{+}$calculated for $\mathrm{C}_{19} \mathrm{H}_{28} \mathrm{NO}_{3}^{+}: 318.2069$, found 318.2078. 2.3b N,N,N-Triethyl-6-(4-methyl-2-oxo-2H-chromen7-yloxy)hexan-1-aminium bromide (21): The product was obtained through column chromatography using silica gel in methanol-chloroform (1:9) to give 21 $(68 \%)$ as a white crystalline solid. $\mathrm{mp}=171-172^{\circ} \mathrm{C}$; $\mathbf{R}_{f}=0.62$ (silica gel, methanol-chloroform (1:4)); UV (acetonitrile) $\lambda_{\max }: 318 \mathrm{~nm}$; IR (KBr) $v_{\max }: 3413.8$, $2978.0, \quad 2942.1, \quad 2850.9, \quad 1716.1,1613.5,1507.9$, $1458.5,1417.8,1388.2,1369.7,1347.5,1278.9$, $1251.7,1199.9,1151.5,1135.7,1072.5,1032.4$, 1002.7, 982.0, 890.0, 878.0, 840.9, 802.5, 711.2, 589.9, $528.9 \mathrm{~cm}^{-1} ;{ }^{1} \mathrm{H}$ NMR $\left(400 \mathrm{MHz}, \mathrm{CDCl}_{3} ; \mathrm{Me}_{4} \mathrm{Si}\right)$ : $\delta 1.32\left(\mathrm{t}, 9 \mathrm{H}, J=7.2 \mathrm{hz},-\mathrm{N}\left(\mathrm{CH}_{2} \mathrm{CH}_{3}\right)_{3}\right), 1.40-1.55$ (m, 4H, H-2 ${ }^{\prime}$ and $\left.\mathrm{H}-3^{\prime}\right), 1.67-1.79\left(\mathrm{~m}, 4 \mathrm{H}, \mathrm{H}-4^{\prime}\right.$ and H-5'), 2.32 (s, 3H, C-4 $\mathrm{CH}_{3}$ ), 3.29 (t, $2 \mathrm{H}, J=6.8 \mathrm{hz}$, H-1'), 3.44 (q, $\left.6 \mathrm{H}, J=6.0 \mathrm{hz},-\mathrm{N}\left(\mathrm{CH}_{2} \mathrm{CH}_{3}\right)_{3}\right), 3.94$ $\left(\mathrm{t}, 2 \mathrm{H}, J=6.6 \mathrm{hz}, \mathrm{H}-6^{\prime}\right), 6.02(\mathrm{~s}, 1 \mathrm{H}, \mathrm{H}-3), 6.67$ (d, $1 \mathrm{H}, J=2.4 \mathrm{hz}, \mathrm{H}-8), 6.78(\mathrm{dd}, 1 \mathrm{H}, J=2.4$ and $8.8 \mathrm{hz}, \mathrm{H}-6), 7.42$ (d, 1H, $J=7.4 \mathrm{hz}, \mathrm{H}-5) ;{ }^{13} \mathrm{C} \mathrm{NMR}$

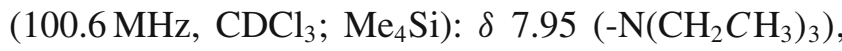
$18.55\left(\mathrm{C}-4 \mathrm{CH}_{3}\right), 21.91,25.42,26.01,28.55\left(\mathrm{C}-2^{\prime}\right.$ $\left.\mathrm{C}-5^{\prime}\right), \quad 53.34\left(-\mathrm{N}\left(\mathrm{CH}_{2} \mathrm{CH}_{3}\right)_{3}\right), \quad 57.31\left(\mathrm{C}-1^{\prime}\right), 67.98$ $\left(\mathrm{C}-6^{\prime}\right), 101.22$ (C-8), 111.46, 112.32 and 113.27 (C-3, C-6 and C-10), 125.53 (C-5), 152.73 and 154.93 (C-4 and C-9), 161.17 (C-7), 161.87 (C-2); HRMS, $m / z: \mathrm{M}^{+}$ calculated for $\mathrm{C}_{22} \mathrm{H}_{34} \mathrm{NO}_{3}^{+}: 360.2539$, found 360.2537 .

2.3c N,N,N-Tributyl-6-(4-methyl-2-oxo-2H-chromen7-yloxy)hexan-1-aminium bromide (22): The product was obtained through column chromatography using silica gel in methanol-chloroform (1:9) to give $\mathbf{2 2}$ $(66 \%)$ as a pale yellow liquid. $\mathrm{R}_{f}=0.76$ (silica gel, methanol-chloroform (1:4)); UV (acetonitrile) $\lambda_{\max }: 319 \mathrm{~nm}$; IR $(\mathrm{KBr}) v_{\max }: 3397.9,2958.7,2873.0$, $1715.2,1613.6,1557.2,1471.1,1388.6,1294.3$, 1202.2, $1145.6, \quad 1071.2, \quad 1015.9, \quad 847.9 \mathrm{~cm}^{-1} ;{ }^{1} \mathrm{H}$ NMR $\left(400 \mathrm{MHz}, \mathrm{CDCl}_{3} ; \mathrm{Me}_{4} \mathrm{Si}\right): \delta 0.95(\mathrm{t}, 9 \mathrm{H}$, $\left.\left.J=7.2 \mathrm{hz},-\mathrm{N}\left(\mathrm{CH}_{2}\right)_{4} \mathrm{CH}_{3}\right)_{3}\right), 1.40-1.41(\mathrm{~m}, 6 \mathrm{H}$, $\left.\left.-\mathrm{N}\left(\mathrm{CH}_{2}\right)_{2} \mathrm{CH}_{2} \mathrm{CH}_{3}\right)_{3}\right), 1.45-1.56\left(\mathrm{~m}, 4 \mathrm{H}, \mathrm{H}-2^{\prime}\right.$ and $\left.\mathrm{H}-3^{\prime}\right), \quad 1.59-1.68\left(\mathrm{~m}, 6 \mathrm{H},-\mathrm{N}\left(\mathrm{CH}_{2} \mathrm{CH}_{2} \mathrm{CH}_{2} \mathrm{CH}_{3}\right)_{3}\right)$, 1.73-1.80 (m, 4H, H-4' and H-5'), 2.34 (s, 3H, C-4 $\left.\mathrm{CH}_{3}\right), 3.32\left(\mathrm{t}, 8 \mathrm{H}, J=7.0 \mathrm{hz},-\mathrm{N}\left(\mathrm{CH}_{2} \mathrm{CH}_{2} \mathrm{CH}_{2} \mathrm{CH}_{3}\right)_{3}\right.$, $\left.\mathrm{H}-1^{\prime}\right), 3.97\left(\mathrm{t}, 2 \mathrm{H}, J=6.6 \mathrm{hz}, \mathrm{H}-6^{\prime}\right), 6.05(\mathrm{~s}, 1 \mathrm{H}$, $\mathrm{H}-3), 6.70(\mathrm{~d}, 1 \mathrm{H}, J=2.4 \mathrm{hz}, \mathrm{H}-8), 6.81(\mathrm{dd}, 1 \mathrm{H}$, $J=2.4$ and $8.8 \mathrm{hz}, \mathrm{H}-6), 7.45(\mathrm{~d}, 1 \mathrm{H}, J=8.8 \mathrm{hz}$, $\mathrm{H}-5) ;{ }^{13} \mathrm{C} \quad \mathrm{NMR} \quad\left(100.6 \mathrm{MHz}, \mathrm{CDCl}_{3} ; \mathrm{Me}_{4} \mathrm{Si}\right)$ : $\delta 13.59\left(-\mathrm{N}\left(\left(\mathrm{CH}_{2}\right)_{3} \mathrm{CH}_{3}\right)_{3}\right), 18.58\left(\mathrm{C}-4 \mathrm{CH}_{3}\right), 19.65$ $\left(-\mathrm{N}\left(\left(\mathrm{CH}_{2}\right)_{2} \mathrm{CH}_{2} \mathrm{CH}_{3}\right)_{3}\right), 22.23\left(-\mathrm{N}\left(\mathrm{CH}_{2} \mathrm{CH}_{2} \mathrm{CH}_{2} \mathrm{CH}_{3}\right)_{3}\right)$, 24.07, 25.52, 26.06, $28.63\left(\mathrm{C}-2^{\prime}-\mathrm{C}-5^{\prime}\right), 58.95$ $\left(-\mathrm{N}\left(\mathrm{CH}_{2}\left(\mathrm{CH}_{2}\right)_{2} \mathrm{CH}_{3}\right)_{3}\right), 59.13\left(\mathrm{C}-6^{\prime}\right), 68.08\left(\mathrm{C}-1^{\prime}\right)$, 101.35 (C-8), 111.54, 112.33 and 113.37 (C-3, C-6 
and C-10), 125.57 (C-5), 152.74 and 155.00 (C-4 and C-9), 161.25 (C-7), 161.93 (C-2); HRMS, $m / z: \mathrm{M}^{+}$ calculated for $\mathrm{C}_{28} \mathrm{H}_{46} \mathrm{NO}_{3}^{+}$: 444.3478, found 444.3492.

$2.3 \mathrm{~d} \quad \mathrm{~N}, \mathrm{~N}, \mathrm{~N}$-Triethyl-10-(4-methyl-2-oxo-2H-chromen7-yloxy)decan-1-aminium bromide (23): The product was obtained through column chromatography using silica gel in methanol-chloroform (1:9) to give $\mathbf{2 3}$ $(65 \%)$ as a white crystalline solid. $\mathrm{mp}=102-104^{\circ} \mathrm{C}$; $\mathbf{R}_{f}=0.43$ (silica gel, methanol-chloroform (1:4)); UV (acetonitrile) $\lambda_{\max }: 317 \mathrm{~nm}$; IR (KBr) $v_{\max }: 3402.89$, $3072.1,2979.1,2924.6,2854.1,1717.8,1612.0$, $1553.2,1472.4,1387.5,1370.7,1343.9,1296.2$, 1278.5, 1263.3, 1202.9, 1149.7, 1070.9, 1017.3, 978.4, 865.1, 800.6, 725.6, 642.0, 566.2, 525.9, $461.2 \mathrm{~cm}^{-1}$; ${ }^{1} \mathrm{H}$ NMR $\left(400 \mathrm{MHz}, \mathrm{CDCl}_{3} ; \mathrm{Me}_{4} \mathrm{Si}\right): \delta$ 1.26-1.40 $\left(\mathrm{m}, 21 \mathrm{H}, \mathrm{H}-2^{\prime}-\mathrm{H}-7^{\prime},-\mathrm{N}\left(\mathrm{CH}_{2} \mathrm{CH}_{3}\right)_{3}\right), 1.63-1.66$ (m, 2H, H-8') 1.73-1.75 (m, 2H, H-9'), 2.35 (s, 3H, C-4 $\left.\mathrm{CH}_{3}\right), 3.22\left(\mathrm{t}, 2 \mathrm{H}, J=7.0 \mathrm{hz}, \mathrm{H}-1^{\prime}\right), 3.44(\mathrm{q}, 6 \mathrm{H}$, $\left.J=6.6 \mathrm{hz},-\mathrm{N}\left(\mathrm{CH}_{2} \mathrm{CH}_{3}\right)_{3}\right), 3.95\left(\mathrm{t}, 2 \mathrm{H}, \mathrm{H}-10^{\prime}\right), 6.05$ $(\mathrm{s}, 1 \mathrm{H}, \mathrm{H}-3), 6.72(\mathrm{~d}, 1 \mathrm{H}, J=2.4 \mathrm{hz}, \mathrm{H}-8), 6.80(\mathrm{dd}$, $1 \mathrm{H}, J=2.4$ and $8.8 \mathrm{hz}, \mathrm{H}-6), 7.45(\mathrm{~d}, 1 \mathrm{H}, J=8.8 \mathrm{hz}$, $\mathrm{H}-5) ;{ }^{13} \mathrm{C} \mathrm{NMR}\left(100.6 \mathrm{MHz}, \mathrm{CDCl}_{3} ; \mathrm{Me}_{4} \mathrm{Si}\right): \delta 7.94$ $\left(-\mathrm{N}\left(\mathrm{CH}_{2} \mathrm{CH}_{3}\right)_{3}\right), 18.59\left(\mathrm{C}-4 \mathrm{CH}_{3}\right), 21.93,25.71,26.33$, 28.73, 28.99, 29.02, 29.14, $30.02\left(\mathrm{C}-2^{\prime}\right.$ - C-9'), 53.36 $\left(-\mathrm{N}\left(\mathrm{CH}_{2} \mathrm{CH}_{3}\right)_{3}\right), 57.36\left(\mathrm{C}-1^{\prime}\right), 68.43\left(\mathrm{C}-10^{\prime}\right), 101.23$ (C-8), 111.48, 112.48 and 113.24 (C-3, C-6 and C-10), 125.48 (C-5), 152.75 and 155.04 (C-4 and C-9), 161.30 (C-7), 162.08 (C-2); HRMS, $m / z: \mathrm{M}^{+}$calculated for $\mathrm{C}_{26} \mathrm{H}_{42} \mathrm{NO}_{3}^{+}$: 416.3165 , found 416.3184 .

\subsection{Biological activity screening}

2.4a Pathogens: Pathogenic strains of Aspergillus, Candida albicans and bacteria were used. Aspergillus fumigatus strain (190/96) was a clinical isolate procured from VP Chest Institute, Delhi (India). Aspergillus niger (ITCC 4), Aspergillus flavus (ITCC5192) and Candida albicans (ITCC 4718) were obtained from Indian Agricultural Research Institute (IARI), New Delhi, India. Various strains of bacteria namely, Pseudomonas aeruginosa (MTCCB 741), Staphylococcus epidermidis (MTCCB 435), Salmonella typhi (MTCCB 733), Staphylococcus aureus (MTCCB 737) were procured from Institute of Microbial Technology, Chandigarh (India).

2.4b Materials: Sabouraud's dextrose agar and Sabouraud's dextrose broth were purchased from Hi Media, Mumbai, India. Amphotericin B, DMSO, Triton X-100, Kanamycin and MTT were procured from
Sigma Chemical Company, USA. Discs for testing were prepared from Whatman filter paper No. 1 from Whatman company (USA).

2.4c Antifungal activity assays: The Aspergillus species and C. albicans were used as model pathogens to study in vitro antifungal activity of compounds. The anti-Aspergillus activity was evaluated by disc diffusion assay (DDA) and microbroth dilution assays (MDA). ${ }^{14}$ For disc diffusion, various concentrations of the compounds prepared by serial dilution were impregnated on sterile Whatman paper 1 discs $5 \mathrm{~mm}$ in diameter, on the surface of Sabouraud dextrose agar already inoculated with Aspergillus spores and zone of inhibition was recorded after $48 \mathrm{~h}$ of incubation at $37^{\circ} \mathrm{C}$. In microbroth assay, serial dilutions of the compounds in Sabouraud dextrose broth were prepared in microtitre plates. Each well was inoculated with $1 \times 10^{6}$ of Aspergillus spores and observed after $48 \mathrm{~h}$. The minimum concentration of the compound which visibly inhibited growth of the fungus was considered as the minimum inhibitory concentration.

The activity against $C$. albicans was determined by basic method of Iijima et al. ${ }^{34}$ suitably modified by Chhillar et al. ${ }^{18}$ The method used was per cent growth inhibition assay. Overnight grown culture of C. albicans at $37^{\circ} \mathrm{C}$ in Saboraud medium was used. Serial dilutions of the compounds were prepared and incubated at $37^{\circ} \mathrm{C}$ for $24 \mathrm{~h}$ and $\mathrm{OD}_{650}$ was measured to determine cell growth. The per cent growth inhibition was calculated using following formula:

$$
\begin{gathered}
\text { PGI = } 100-(\text { OD in drug treated well } / \mathrm{OD} \\
\text { in control well }) \times 100 .
\end{gathered}
$$

2.4d Antibacterial activity: The activity of compounds against pathogenic bacteria was assessed by MDA and DDA as described by Riffel et al. ${ }^{35}$ suitably modified in our laboratory by Chaudhary et al. ${ }^{36}$ Briefly, the inoculum was prepared by growing bacteria at $37^{\circ} \mathrm{C}$ for $12-14 \mathrm{~h}$. The OD of overnight culture was adjusted to 0.09 to 0.10 (equivalent to a $0.5 \mathrm{McFarland}$ standard) at a transmission wavelength of $600 \mathrm{~nm}$. The test was performed in 96 well-flat bottom culture plates (Nunc, Nunclon). Pathogen in microwells treated with various concentrations of the compounds was incubated at $37^{\circ} \mathrm{C}$ for $12 \mathrm{~h}$ and absorbance at $600 \mathrm{~nm}$ was measured to determine the bacterial growth. Kanamycin was used in the assay as the standard control drugs. An additional control well without any sample but with an equivalent amount of solvent was used as reference 
in the assay. For disc diffusion, Whatman filter paper No. 1 discs $(5.0 \mathrm{~mm}$ in diameter) were impregnated with dilutions of compounds and incubated at $37^{\circ} \mathrm{C}$ and examined for zone of inhibition.

2.4e Haemolytic activity: The in vitro cell cytotoxicity of the active compounds was evaluated by using slightly modified haemolytic assay of Latoud et al. ${ }^{37}$ Human erythrocytes, collected from apparently healthy individual were washed and suspended in phosphate buffer saline (PBS). Erythrocyte suspension (2\% v/v) in PBS was incubated with different concentrations of compound at $37^{\circ} \mathrm{C}$ for $1 \mathrm{~h}$. After incubation, cells were pelleted at $3000 \mathrm{~g}$ for $10 \mathrm{~min}$. The supernatant was collected and $\mathrm{OD}_{450}$ was determined using a spectrophotometer (Spectra Max 384 plus, Molecular Devices). PBS was used as negative control and Triton X-100 was used for completely lysing the cells. The per cent haemolysis was calculated using the following formula:

$$
\begin{aligned}
& \text { Percent haemolysis } \\
& \quad=100-(\mathrm{OD} \text { of test } / \mathrm{OD} \text { of control }) \times 100 .
\end{aligned}
$$

The percent haemolysis was plotted against concentration of compound to determine the dose cytotoxic to erythrocytes.

2.4f MTT assay: The method described by Mosmann (1983) was followed. ${ }^{38}$ Cells were maintained in RPMI-1640 medium supplemented with glutamine and fetal calf serum $(10 \% \mathrm{v} / \mathrm{v})$ and were harvested at the log phase of confluency from the flask. The assay was performed in 96-well flat bottom tissue culture plates (Nunc, Nunclon). The cells $\left(2 \times 10^{4}\right)$ in $100.0 \mu \mathrm{l}$ of media were seeded into each well for overnight. Dilutions of compounds were added and incubated at $37^{\circ} \mathrm{C}$ in atmosphere of $5 \%(\mathrm{v} / \mathrm{v}) \mathrm{CO}_{2}$ for $24 \mathrm{~h}$. In negative control, equivalent amount of the solvent was used in each well. After removing the medium the cells were treated with $10.0 \mu \mathrm{l}$ of $5 \mathrm{mg} / \mathrm{ml}$ (stock) of 3-(4,5-dimethylthiazol-2-yl)-2,5-diphenyltetrazolium bromide (MTT). After adding the dye to the wells, the plate was kept at $37^{\circ} \mathrm{C}$ in $5 \% \mathrm{CO}_{2}$ for $4 \mathrm{~h}$. The dye was removed from the wells and the cells were lysed by adding $100.0 \mu \mathrm{l}$ of DMSO. The wells were read at $540 \mathrm{~nm}$ using plate reader (SpectraMax 384 plus, Molecular Devices). The per cent toxicity with respect to the negative control was calculated and plotted against concentrations of the compound.

\section{Results and discussion}

\subsection{Chemistry}

The synthesis of ammonium acyloxy derivatives of chromen-2-ones, quinolin-2-ones and chromen-4-ones is outlined in scheme 1 . They were synthesized in two steps i.e., first the hydroxy chromenone/quinolinones were treated with bromo acyl chloride in presence of triethylamine. The bromo acyl chloride in turn was prepared from corresponding bromo acid by treating with oxalyl chloride. In the next step the bromo acyloxy chromenones/quinolinones were treated with excess of triethylamine in anhydrous acetonitrile under refluxing conditions (scheme 1).

The synthesis of ammonium alkoxy derivatives 17-19 is outlined in scheme 2. They were synthesized by the reaction of terminal dihalo alkanes with 7-hydroxy-4-methyl- $2 H$-chromen-2-one in the presence of potassium carbonate and acetone under reflux conditions. The corresponding ammonium compounds (20-23, scheme 2) were then prepared by treating them with triethyl/tributylamine in a mixture of toluene, acetone and DMF (in a ratio of 4:4:2) under reflux conditions.

A total of 12 ammonium chromenones/quinolinones and their 11 precursors i.e., the corresponding halo analogs were synthesized, of these compounds 1-16 and 19-23 are novel. All the compounds were fully characterized on the basis of their physical and spectral data. The structures of known compounds $\mathbf{1 7}^{32}$ and $\mathbf{1 8}^{33}$ were confirmed by comparison of their melting points and spectral data with those reported in the literature.

\subsection{Antimicrobial activity}

The synthesized ammonium derivatives and their halo precursors (1-23) were then screened for antimicrobial activity against pathogenic fungi (Aspergillus fumigatus, Aspergillus flavus, Aspergillus niger, Candida albicans) and bacteria (Staphylococcus aureus, Staphylococcus epidermidis, Pseudomonas aeruginosa, Salmonella typhi). The antimicrobial activity screening of all the compounds was performed according to the established methods described in the literature. ${ }^{14,18,34-36}$

Most of the ammonium compounds screened were found to possess a broad spectrum of activity against the pathogens while the halogenated precursors (1-8, 17-19) of the ammonium compounds were not active against the bacterial pathogens within the range of the concentrations tested. However, six compounds 


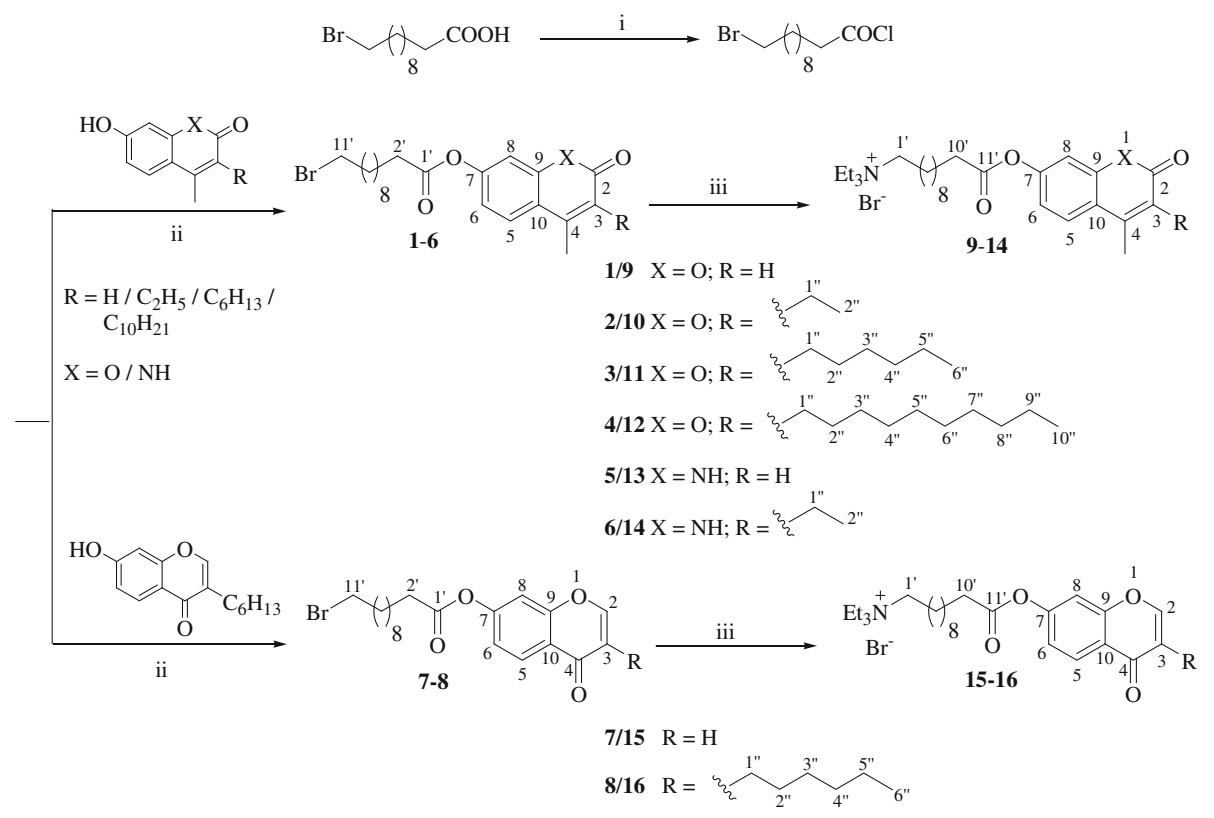

Scheme 1. Synthesis of $N, N, N$-triethyl-11-(3-alkyl-4-methyl-2-oxo-2 $H$-chromen/ 1,2-dihydro quinolin/4-oxo-4H-chromen-7-yloxy)-11-oxoundecan-1-aminium bromide. (i) $(\mathrm{COCl})_{2}, \mathrm{DCM}$; (ii) $\mathrm{NEt}_{3}$ (1.0 equivalent), $\mathrm{CH}_{3} \mathrm{CN}, 37^{\circ} \mathrm{C}$; (iii) $\mathrm{NEt}_{3}$ (5.0 equivalent), $\mathrm{CH}_{3} \mathrm{CN}, 60^{\circ} \mathrm{C}$.

i.e., five haloacyloxy chromenones $(\mathbf{2}-\mathbf{4}, \mathbf{7 - 8})$ and two haloalkoxy chromenones $(\mathbf{1 5}, \mathbf{1 6})$ were found to be active against most of the fungal strains. The haloacyloxy chromenones $(\mathbf{2}-\mathbf{4}, \mathbf{7}-\mathbf{8})$ were found to have moderate activity against all the species of fungi tested, while the haloalkoxy derivatives $(\mathbf{1 5}, \mathbf{1 6})$ were found to be active against selective species only, however these will have more potent activities. This fact was substantiated by the observations that the acyloxy derivatives $(\mathbf{2}-\mathbf{4}, \mathbf{7}-\mathbf{8})$ were active against all the four fungal strains, with compound $\mathbf{3}$ having the maximum activity against $A$. niger at a MIC of $31.25 \mu \mathrm{g} / \mathrm{ml}$ in MDA and $7.81 \mu \mathrm{g} /$ disc in DDA. While, among the alkoxy derivatives, the compound $\mathbf{1 8}$ had a narrow range of activity against only two pathogenic fungi i.e., A. niger and A. flavus, it was found to be most effective against A. niger at a concentration of $15.62 \mu \mathrm{g} / \mathrm{ml}$ in MDA and $1.95 \mu \mathrm{g} / \mathrm{disc}$ in DDA (table 1). The haloacyloxy derivatives of quinolin-2-ones $(\mathbf{5}, \mathbf{6})$ were found to be completely inactive against all the fungal pathogens.

An in-depth antimicrobial study of the ammonium acyloxy derivatives of chromen-2-ones (9-12) showed interesting results. These compounds showed a promising broad spectrum of activity against most of the pathogens. Amongst them the compound $\mathbf{1 1}$ having a $\mathrm{C}_{6}$ alkyl chain at the $\mathrm{C}-3$ position of pyran ring was strikingly the most active compound, it showed remarkably good activity against Aspergillus species i.e., exhibited a MIC of $12.50 \mu \mathrm{g} / \mathrm{ml}$ against $A$. fumigatus, $7.81 \mu \mathrm{g} / \mathrm{ml}$ against $A$. niger and $31.25 \mu \mathrm{g} / \mathrm{ml}$ against $A$. flavus in MDA while in DDA the MICs were $1.95 \mu \mathrm{g} / \mathrm{disc}, 1.95 \mu \mathrm{g} / \mathrm{disc}$ and $15.62 \mu \mathrm{g} / \mathrm{disc}$, respectively. Its activity against $C$. albicans was observed to be $7.81 \mu \mathrm{g} / \mathrm{ml}$. Also, the compound $\mathbf{1 1}$ was found
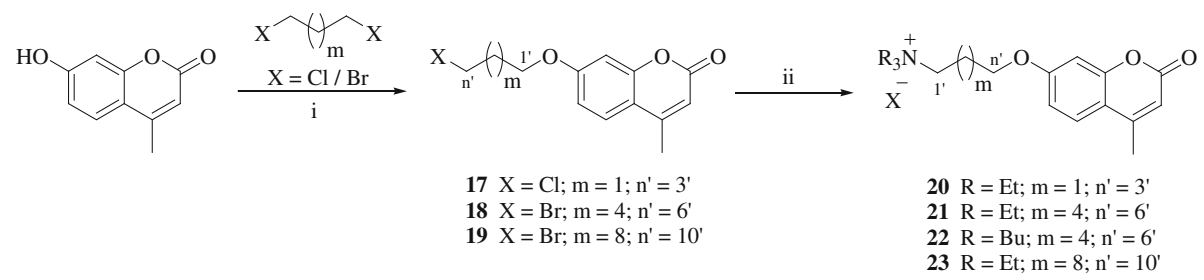

Scheme 2. Synthesis of $N, N, N$-triethyl/butyl-3-(4-methyl-2-oxo-2 $H$-chromen-7yloxy)alkan-1-aminium halide. (i) $\mathrm{K}_{2} \mathrm{CO}_{3}$, Acetone; (ii) $\mathrm{NEt}_{3}$ (5.0 equivalent), $\mathrm{CH}_{3} \mathrm{CN}, 60^{\circ} \mathrm{C}$. 


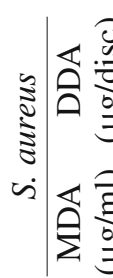

$: \widetilde{0}$

ิำ

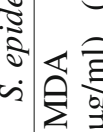

$\mid \begin{aligned} & 0 \\ & 0 \\ & 0\end{aligned}$

₹

$\varangle \widehat{\xi}$

事

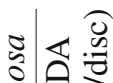

जิ

¿

Q

悹

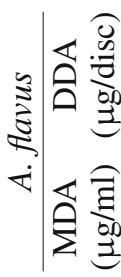

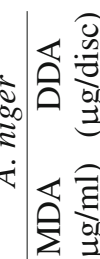

更

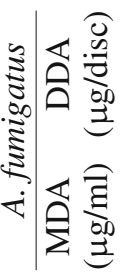

$\sigma_{1} \sigma_{1} \sigma_{1} \sigma_{1} \sigma_{1} \sigma_{1} \sigma$

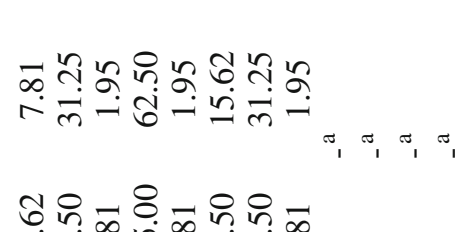

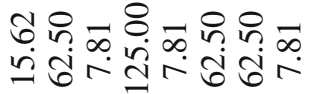

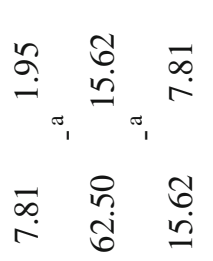

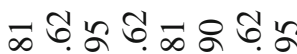

車

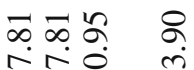

$\approx \pi, \pi, \pi, \pi, \pi, \pi$

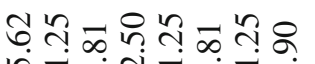

जिंतुलंखें

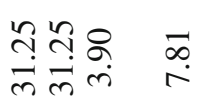

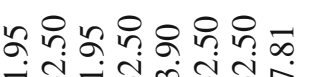

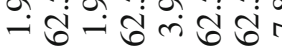

尚

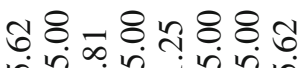

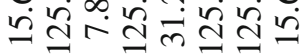

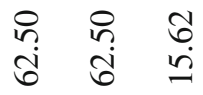

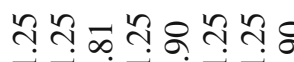

mলñ

ํํํํํำำ ำ ำ

สู่ ชู่

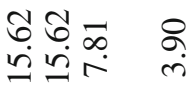

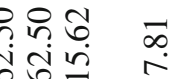

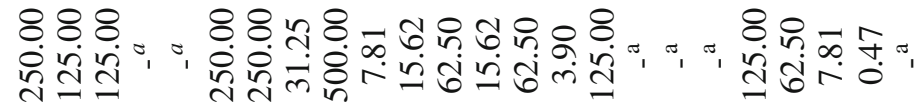

8 요

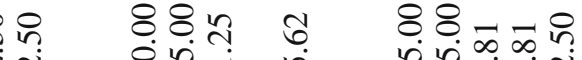

ปู่

888

ปู่

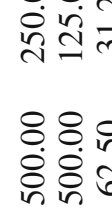

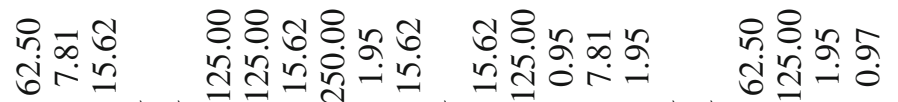
ॠ

৪ُ ำ

$88.8 \div$

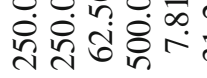

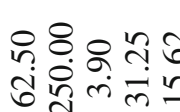

$\approx \pi$

8ㅇํำ

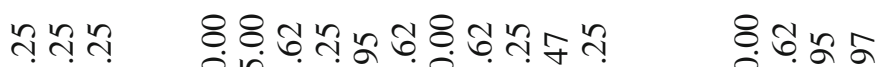

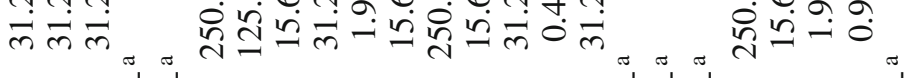

$\pi_{1}$

$8: 8$

ปู่

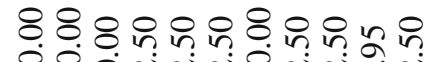

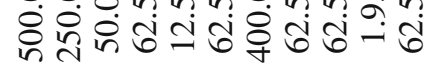

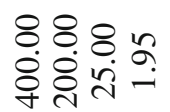

离

คิ 
to possess significant antibacterial activity. It exhibited a MIC of $15.62 \mu \mathrm{g} / \mathrm{ml}$ in MDA and $7.81 \mu \mathrm{g} / \mathrm{disc}$ in DDA against $P$. aeruginosa and $7.81 \mu \mathrm{g} / \mathrm{ml}$ in MDA and $1.95 \mu \mathrm{g} /$ disc in DDA against $S$. typhi, S. epidermidis and $S$. aureus (table 1). The compound 9 that lacks a substitution at the C-3 position was also observed to have a reasonably good antimicrobial activity against all the pathogenic species in comparison to compounds $\mathbf{1 0}$ and $\mathbf{1 2}$ that have a $\mathrm{C}_{2}$ and $\mathrm{C}_{10}$ alkyl chain at the $\mathrm{C}-3$ position of pyran ring respectively (table 1 ). The above results suggested that hexyl is the optimum chain length at C-3 position in ammonium derivatives of chromen-2-ones to exhibit antimicrobial activity.

Encouraged by these results, the chromen-4-one derivative 15-16 were synthesized and screened for the antimicrobial activity. The compound $\mathbf{1 6}$ having a hexyl chain at the $\mathrm{C}-3$ position of the chromen-4-one nucleus was found to be more active than its unsubstituted counterpart $\mathbf{1 5}$ and showed even better activity than the compound 11 (chromen-2-one) against all the pathogenic strains. It exhibited an MIC of $1.95 \mu \mathrm{g} / \mathrm{ml}$ against $A$. fumigatus, $3.90 \mu \mathrm{g} / \mathrm{ml}$ against $A$. niger and $15.62 \mu \mathrm{g} / \mathrm{ml}$ against $A$. flavus in MDA, while in DDA the respective MIC values were $0.47 \mu \mathrm{g} / \mathrm{disc}, 0.95 \mu \mathrm{g} / \mathrm{disc}$ and $7.81 \mu \mathrm{g} / \mathrm{disc}$. It was found to be active against C. albicans at $3.90 \mu \mathrm{g} / \mathrm{ml}$. It also exhibited good antibacterial activities against $P$. aeruginosa and $S$. epidermidis at a MIC of $7.81 \mu \mathrm{g} / \mathrm{ml}$ and $3.90 \mu \mathrm{g} / \mathrm{ml}$ in MDA, while $3.90 \mu \mathrm{g} / \mathrm{disc}$ and $1.95 \mu \mathrm{g} / \mathrm{disc}$, respectively in DDA (table 1). These results further substantiated the fact that the antimicrobial activity of chromenones may be enhanced by having an alkyl chain of approximately six carbon units. The target site for the antimicrobial activity is the cell membrane where the antimicrobial compound disrupts the ordered structure of the phospholipid bilayer causing leakage of the bacterial membrane. The hydrophobic interactions due to alkyl groups at C-3 position such as hexyl might be facilitating this process and as a result loss of outer membrane leaves the bacteria vulnerable against all external threats. Further exposure to the ammonium compounds disrupts the inner membrane and lyses the microbe. A detailed study of mechanism is under investigation.

Among the ammonium alkoxy derivatives 20-23, compound 20 having a triethyl ammonium propoxy ether chain at the $\mathrm{C}-7$ position of chromenone skeleton was found to be inactive against all the pathogens. Although on elongation of the alkyl chain to six carbon unit, i.e., in compounds $\mathbf{2 1}$ and $\mathbf{2 2}$, an improvement in the antimicrobial activity was observed. The small size of alkyl chain in these compounds (20-22) may be responsible for their lower activity and thus supports the general hypothesis that the ammonium compounds possessing an aliphatic alkyl chain of less than eight carbons are not much active. ${ }^{39,40}$ We have also noticed that the increase in the chain length of the polar head group in the ammonium moiety from two carbon atoms (triethyl) in compound $\mathbf{2 1}$ to four carbon atoms (tributyl) in compound $\mathbf{2 2}$ did not exhibit any noticeable change in the antimicrobial activity. A significant enhancement in the antimicrobial activity was, however observed for compound 23 having a $\mathrm{C}_{10}$ alkyl chain. It exhibited a MIC of $25.00 \mu \mathrm{g} / \mathrm{ml}$ against A. fumigatus in MDA. Slightly higher concentration $(31.25 \mu \mathrm{g} / \mathrm{ml})$ of $\mathbf{2 3}$ was

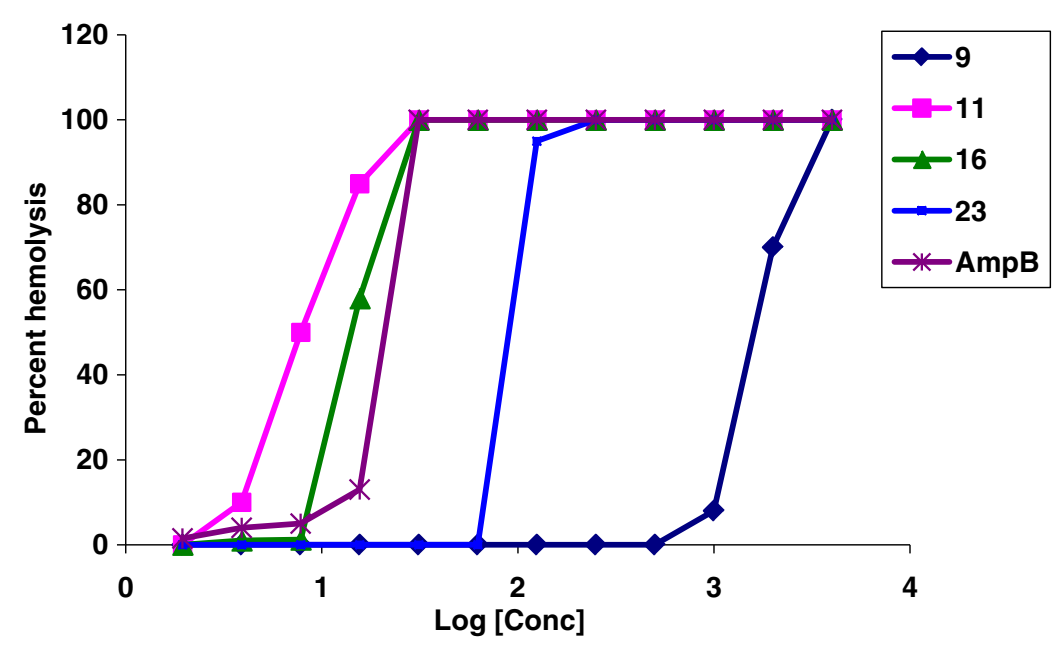

Figure 1. Cytotoxicity of active compounds against human erythrocytes by hemolytic assay. 


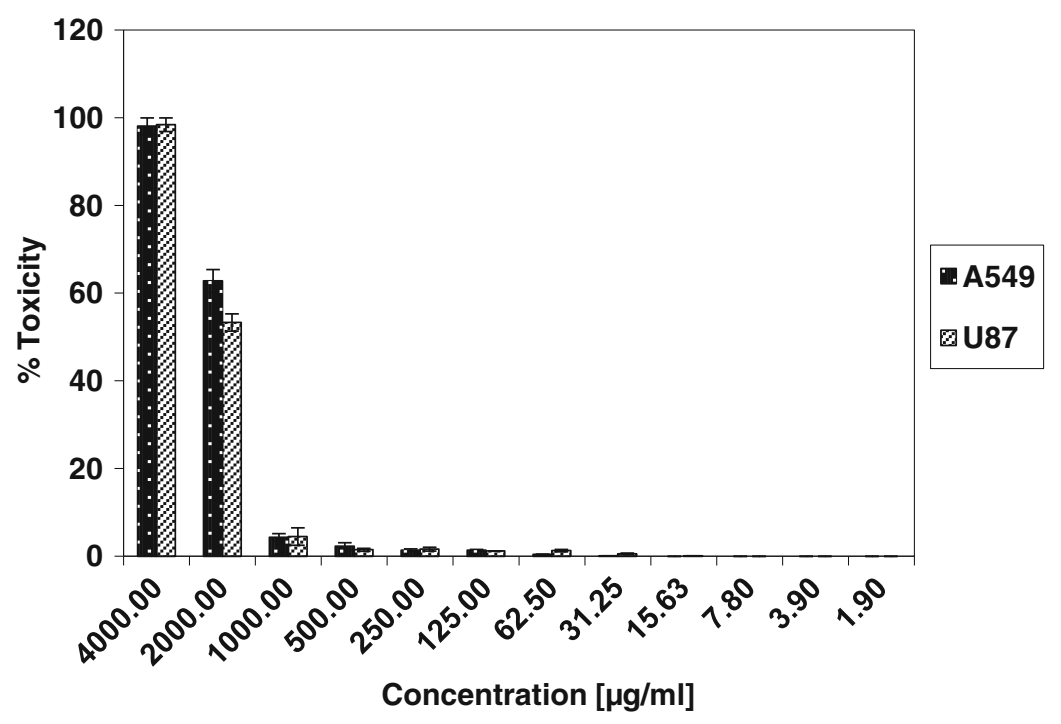

Figure 2. Cytotoxicity evaluation of compound $\mathbf{9}$ on viability of mammalian cell lines by MTT assay.

required to completely inhibit the growth of $A$. niger and A. flavus. The MICs in DDA were $1.95 \mu \mathrm{g} / \mathrm{disc}$ against all the species of Aspergilli, and $7.81 \mu \mathrm{g} / \mathrm{ml}$ against $C$. albicans. It also showed promising antibacterial activity against two bacterial species, i.e., $P$. aeruginosa and $S$. epidermidis at a MIC of $15.62 \mu \mathrm{g} / \mathrm{ml}, 3.90 \mu \mathrm{g} / \mathrm{ml}$ in MDA and $7.81 \mu \mathrm{g} / \mathrm{disc}$ and $0.95 \mu \mathrm{g} /$ disc in DDA, respectively (table 1).

The ammonium acyloxy derivatives of quinolin-2ones $(\mathbf{1 3}, \mathbf{1 4})$ were also synthesized and their antimicrobial activity was evaluated. Of these, the compound $\mathbf{1 3}$ was active against only $A$. fumigatus and $C$. albicans, the substitution at the $\mathrm{C}-3$ position of the quinolin-2-one moiety (14) increased the antimicrobial spectrum.

The antimicrobial potency of these compounds was compared with the standard antifungal drug, amphotericin B and the antibiotic drug kanamycin as controls (table 1). Among all the compounds screened, the ammonium derivative $\mathbf{1 6}$ showed remarkable activities against all the fungal and bacterial strains. The next most active compound was $\mathbf{1 1}$, followed by $\mathbf{2 3}$ and $\mathbf{9}$.

\subsection{Cytotoxicity studies}

The four most promising ammonium compounds i.e., 9, 11, 16 and 23 were further investigated for their cytotoxicity on the viability of human erythrocytes by hemolytic assay ${ }^{37}$ and mammalian cell lines by MTT assay. ${ }^{38}$ The serial dilutions of the compounds prepared in phosphate buffer saline were incubated with erythrocytes and the effect was studied. The per cent toxicity of the cells was plotted with log concentrations of the compound. The MTT assay was performed on two mammalian cell lines, human lung epithelial cells (A549) and human glioma cells (U87) and the percent viability was determined.

The compounds $\mathbf{1 1}$ and $\mathbf{1 6}$ were found to be quite toxic to the erythrocytes, a concentration of $31.25 \mu \mathrm{g} / \mathrm{ml}$ of each lysed all the cells. Compound $\mathbf{2 3}$ was comparatively less toxic than $\mathbf{1 1}$ and $\mathbf{1 6}$ (figure 1). However, amongst all, the compound 9 was least toxic, it exhibited only marginal toxicity $(\sim 15 \%)$ at $1000 \mu \mathrm{g} / \mathrm{ml}$ and was non-toxic at $500 \mu \mathrm{g} / \mathrm{ml}$ (figure 1), thus suggesting it to be safer than the standard drug amphotericin B, which caused complete lysis of erythrocytes at a concentration of $31.25 \mu \mathrm{g} / \mathrm{ml}$.

Given the low haemolytic activity of the compound 9, it was of interest to determine its broader cytotoxicity against other mammalian cells. Its effect on the viability of two mammalian cell lines, human lung epithelial cells (A549) and human glioma cell line (U87) was determined by MTT [3-(4,5-dimethylthiazol-2-yl)2,5-diphenyltetrazolium bromide] assay. The results showed that the mammalian cells tolerated the compound up to a concentration of $1000 \mu \mathrm{g} / \mathrm{ml}$ whereas the standard drug amphotericin B was many fold toxic (figure 2).

\section{Conclusions}

In summary, we have carried out the synthesis of a series of novel ammonium derivatives of 
chromen-2-ones, quinolin-2-ones and chromen-4-ones, which showed significant activity against the bacterial and fungal pathogens tested, paving the way for novel chromenones and quinilinones to be used as antimicrobial agents. Amongst the ammonium compounds synthesized, four compounds viz., $N, N, N$-triethyl-11-(4methyl-2-oxo- $2 H$-chromen-7-yloxy)-11-oxoundecan1-aminium bromide (9) and $N, N, N$-triethyl-11-(3hexyl-4-methyl-2-oxo-2 $H$-chromen-7-yloxy)-11-oxoundecan-1-aminium bromide (11), $N, N, N$-triethyl11-(3-hexyl-4-oxo-4H-chromen-7-yloxy)-11-oxoundecan-1-aminium bromide (16) and $N, N, N$-triethyl10-(4-methyl-2-oxo-2 $H$-chromen-7-yloxy)decan-1aminium bromide (23) were found to be most promising. Cytotoxicity study results showed the compounds 11, 16 and 23 to be toxic. Although the potency of the compound $\mathbf{9}$ is less than that of the commercial drugs amphotericin B and kanamycin, it was found to have a broader range of activity than these drugs among the fungal and bacterial strains tested. Also the cytotoxicity studies revealed that the compound 9 was much safer than the standard antifungal drug amphotericin B. Thus, this compound can be taken up further for suitable modifications and for the development of more promising analogues having higher therapeutic index.

\section{Acknowledgements}

Financial support from the Defence Research and Development Organization (DRDO), Govt. of India and University of Delhi is gratefully acknowledged. We are also thankful to the Council of Scientific and Industrial Research (CSIR), New Delhi for awarding SRF to S Gupta, S Singh, A Kathuria and A Gupta.

\section{References}

1. Rasko D A and Sperandio V 2010 Nat. Rev. Drug Discovery 9117

2. Saleem M, Nazir M, Ali M S, Hussain H, Lee Y S, Riaz N and Jabbar A 2010 Nat. Prod. Rep. 27238

3. Denning D W 1998 Clin. Infect. Dis. 26781

4. Perea S and Patterson T F 2002 Semin. Respir. Infect. 17 99

5. Hage C A, Goldman M and Wheat L J 2002 Eur. J. Med. Res. 7236

6. Projan S J and Bradford P A 2007 Curr. Opin. Microbiol. 10441

7. Johnson K W, Lofland D and Moser H E 2005 Curr. Drug Targets-Infect. Disord. 539
8. Lass-flörl C, Speth C, Mayr A, Würzner R, Dierich M P, Ulmer H and Dietrich H 2003 Diagnostic Microbiol. Infect. Dis. 47569

9. Groll A H, De Lucca A J and Walsh T J 1998 Trends Microbiol. 6117

10. Kauffman C A and Carver P L 1997 Drugs 53 539

11. Vandane B H, Dromer F, Improvisi I, Lozano-Chiu M, Rex J H and Sanglard D 1998 Med. Mycol. 36119

12. Klepser M E, Ernst E J and Pfaller M A 1997 Trends Microbiol. 5372

13. Ator M A, Schmidt S J, Adams J L, Dolle R E, Kruse L I, Frey C L and Barone J M 1992 J. Med. Chem. 35100

14. Dabur R and Sharma G L 2002 J. Ethnopharmacol. 80 193

15. Dabur R, Chhillar A K, Yadav V, Kamal P K, Gupta J and Sharma G L 2005 J. Med. Microbiol. 54549

16. Dabur R, Diwedi S K, Yadav V, Mishra V, Singh R, Singh H and Sharma G L 2005 Antimicrob. Agents Chemo. 494365

17. Dabur R, Mandal T K and Sharma G L 2007 J. Med. Microbiol. 56815

18. Chhillar A K, Arya P, Mukherjee C, Kumar P, Yadav Y, Sharma A K, Yadav V, Gupta J, Dabur R, Jha H N, Watterson A C, Parmar V S, Prasad A K and Sharma G L 2006 Bioorg. Med. Chem. 14973

19. Kumar A, Singh B K, Sharma N K, Gyanda K, Jain S K, Tyagi Y K, Baghel A S, Pandey M K, Sharma S K, Prasad A K, Jain S C, Rastogi R C, Raj H G, Watterson A C, Eycken E V and Parmar V S 2007 Eur. J. Med. Chem. 42447

20. Kathuria A, Gupta A, Priya N, Singh P, Raj H G, Prasad A K, Parmar V S and Sharma S K 2009 Bioorg. Med. Chem. 171550

21. Priya N, Gupta A, Chand K, Singh P, Kathuria A, Raj H G, Parmar V S and Sharma SK 2010 Bioorg. Med. Chem. 184085

22. Kumar S, Singh B K, Pandey A K, Kumar A, Sharma S K, Raj H G, Prasad A K, Eycken E V, Parmar V S and Ghosh B 2007 Bioorg. Med. Chem. 152952

23. Petrocci A N 1983 Surface-Active Agents: Ammonium Compounds, in: S S Block (ed.), Disinfection, Sterilization and Preservation; 3rd ed.; Philadelphia: Lea and Febiger, pp. 309-329

24. Huyck C L 1944 Am. J. Pharm. 11650

25. Bodor N and Kaminski J J 1980 J. Med. Chem. 23566

26. Bodor N, Woods R, Raper C, Kearney P and Kaminski J J 1980 J. Med. Chem. 23474

27. Bodor N and Buchwald P 2000 Med. Res. Rev. 2058

28. Calvani M, Critelli L, Gallo G, Giorgi F, Gramiccioli G, Santaniello M, Scafetta N, Tinti M O and De Angelis F 1998 J. Med. Chem. 412227

29. Pechmann H V and Duisberg C 1883 Chem. Ber. 16 2119

30. Staskun B 1964 J. Org. Chem. 291153

31. Jain A C, Tyagi O D and Saksena R 1989 Ind. J. Chem. 28B 678

32. Shelke S M, Sushilkumar, Sati N, Veer V S, Bhosale S H, Bodhankar S L, Mahadik K R and Kadam S S 2005 Ind. J. Chem. 44B 2295 
33. Shinde D B and Shingare M S 1994 Asian J. Chem. 6265

34. Iijima R, Kurata S and Natori S 1993 J. Biol. Chem. 268 12055

35. Riffel A, Medina L F, Stefani V, Santos R C, Bizani D and Brandelli A 2002 Braz. J. Med. Biol. Res. 35811

36. Chaudhary P, Kumar R, Verma A K, Singh D, Yadav V, Chhillar A K, Sharma G L and Chandra R 2006 Bioorg. Med. Chem. 141819
37. Latoud C, Peypoux F, Michel G, Genet R and Morgat J L 1986 Biochem. Biophys. Acta 856526

38. Mosmann T 1983 J. Immunol. Methods 6555

39. Thorsteinsson $\mathrm{T}$, Masson $\mathrm{M}$, Kristinsson $\mathrm{K} \mathrm{G}$, Hjalmarsdottir M A, Hilmarsson H and Loftsson T 2003 J. Med. Chem. 464173

40. Thorsteinsson T, Loftsson T and Masson, M 2003 Current Med. Chem. 101129 